\title{
Optimum Network Reconfiguration to Improve Power Quality and Reliability in Distribution System
}

\author{
${ }^{1}$ Arash Bashardoust, ${ }^{2}$ Meisam Farrokhifar, \\ ${ }^{3}$ Amin Yousefzadeh Fard, ${ }^{4}$ Amin Safari, \\ ${ }^{5}$ Ehsan Mokhtarpour \\ ${ }^{1}$ Department of Electrical Engineering, \\ Heris Branch, Islamic Azad University, Heris, Iran. \\ ${ }^{2}$ Department of Electrical Engineering, \\ Heris Branch, Islamic Azad University, Heris, Iran. \\ ${ }^{3}$ Department of Electrical and Computer Engineering, \\ University of Tabriz,Tabriz, Iran. \\ ${ }^{4}$ Department of Electrical Engineering, \\ Azarbaijan Shahid Madani University, Tabriz, Iran. \\ ${ }^{5}$ Department of Electrical Engineering, \\ Azarbaijan Shahid Madani University, Tabriz, Iran. \\ 2farrokhifar@herisiau.ac.ir, ${ }^{4}$ safari@azaruniv.edu
}

\begin{abstract}
In this paper, network reconfiguration has been conducted to improve the power quality and reliability of distribution systems in presence of distributed generations. In this case, network reconfiguration is analyzed for different indices. The most important indices are the number of propagated voltage sags $(N$ sag), sustained average interruption frequency index, average system interruption frequency index and momentary average interruption frequency index. The Imperialist competitive algorithm (ICA) is hired to find the optimal configuration of the distribution system in order to minimize the mentioned indices. Simulation result is discussed with and without distributed generation.
\end{abstract}

Keywords: Power Quality, Reliability, Imperialist Competitive Algorithm, Distributed Generation,s Reconfiguration

\section{Introduction}

In recent years, electrical industry has undergone fundamental changes. Reliability and quality of power delivered to the customers has become very important issues. On the other hand, power loss is an issue that needs to be considered and reduced as much as is possible. One way to increase the power quality and the reliability of distribution networks is to optimize the network configuration. Reconfiguration of electrical distribution networks, especially in the presence of automation systems is an operational goal. In addition, presence of distributed generation can significantly increase quality level of the network.

Many researches with different goals to find the optimum network configuration have been done in recent years. For example, [1] has used a feeder transfer scheme to moderate voltage sag propagation in distribution systems. The improved genetic algorithm GA is used to find new optimum topologies with minimum power losses [2]. Improvement of power losses and voltage profile in power distribution networks by applying differential evolution algorithm for optimal network reconfiguration and DSTATCOM allocations is done in [3]. In [4], genetic algorithm is applied to achieve minimized losses in 
Distribution Networks considering variable behavior of loads and energy cost curves. Combination of network reconfiguration and DSTATCOM placement to reduce voltage sag problem, is also analyzed with an integrated method [5-7]. In [8], network reconfiguration is conducted with differential evolution algorithm to increase power quality subjects such as harmonics and voltage sags. Power loss is the other matter that is analyzed in this paper. Evaluation of distribution system reliability is analyzed by developing a reliability enhancement algorithm in [9].This paper has considered uncertainties in loads, power generation, and electrical and reliability parameters to improve system reliability and reduce losses in distribution system. Bacterial foraging optimization algorithm is used for loss minimization of distribution network with network reconfiguration [10]. A Self-adaptive modified teacher learning optimization (MTLO) has been addressed to solve a multi-objective optimization network reconfiguration problem [11]. Total cost, power loss and wind uncertainty has been considered in this paper. Optimal power loss, total cost, and total emission of a fuel cell power plant are the goals of network reconfiguration in [12] using modified teacher learning optimization. Reliability indices by network reconfiguration are also analyzed in this paper.

Voltage sags often cause load outages. So, the reliability indices of the distribution systems are adversely affected by voltage sag propagation. In this paper, optimization of network configuration in order to improve power quality and reliability in presence of distributed generation has been analyzed. Reliability indices are SAIFI ،ASIFI ‘MAIFI and the power quality index is $\mathrm{N}_{\text {sag. }}$. Imperialist competitive algorithm is used to reduce active power losses, number of voltage sag and improve reliability indices in a distribution test system. Results in presence and absence of distributed generation are discussed.

\section{PQ and Reliability Assessment Indices}

The main goal of the operators is to deliver a high quality power to consumers. So, power quality indices are very important to be analyzed. In this case, number of propagated voltage sags $\left(\mathrm{N}_{\mathrm{sag}}\right)$ and the total number of interruptions $\left(\mathrm{N}_{\mathrm{int}}\right)$ are calculated by monitoring each bus's voltage magnitude $\left(\mathrm{V}_{\mathrm{i}}\right)$ for the test system. Annual $\mathrm{N}_{\text {sag }}$ can be obtained as follows [13, 14]:

$$
\text { Nsag }=\sum_{\mathrm{i}=1}^{\mathrm{Nbus}} \sum_{\mathrm{f}=1}^{\mathrm{Ftotal}}\left\{\begin{array}{lr}
1 & \text { if } 0.1 \mathrm{p} . \mathrm{u}<V i<0.9 \text { p.u } \\
0 & \text { otherwise }
\end{array}\right.
$$

The total number of continued interruptions for sensitive buses is equal to $\mathrm{N}_{\mathrm{sag}}$ and the total number of interruptions per year for non-sensitive loads is assumed as follows [13, 14]:

$$
\text { Nint }=\sum_{\mathrm{i}=1}^{\mathrm{Nbus}} \sum_{\mathrm{f}=1}^{\mathrm{Ftotal}}\left\{\begin{array}{lr}
1 & \text { if } \quad V i<0.1 p . u \\
0 & \text { otherwise }
\end{array}\right.
$$

Reliability indices of distribution systems are categorized into three groups. The SAIFI is a short-term index, ASIFI indicate load-related indices and MAIFI represents continued interruption [15].

$$
\begin{aligned}
& S A I F I=\frac{\text { sum of all customer continued interruptions due to each event }}{\text { total number of customers served }} \\
& A S I F I=\frac{\text { sum of total connected KVA of load interrupted }}{\text { total connected KVA served }} \\
& M A I F I=\frac{\text { sum of customer short-term interrupted }}{\text { total number of customers served }}
\end{aligned}
$$

The SAIFI determines the sustained customer interruptions, ASIFI defines the financial losses caused by load outages and MAIFI shows customer disruption because of protection device operations. 


\section{Imperialist Competitive Algorithm}

Recently, evolutional algorithms have been widely used in problem optimization. Among these algorithms, the Imperialist Competitive Algorithm has been inspired by a social phenomenon unlike other optimization algorithms which have been generally adopted from a natural phenomenon. This algorithm was presented in [16]. Considering the historical phenomenon of colonization in order to achieve the social-political development in human societies and consequently, the mathematical modeling of this process, the algorithm has been proposed as a powerful evolutionary approach for the optimization of problems. According to Figure 1, a number of random initial populations are called as countries for the algorithm in the first stage. Meanwhile, a number of the most powerful countries (the most cost-effective) are selected as imperialists and the rest as colonies.

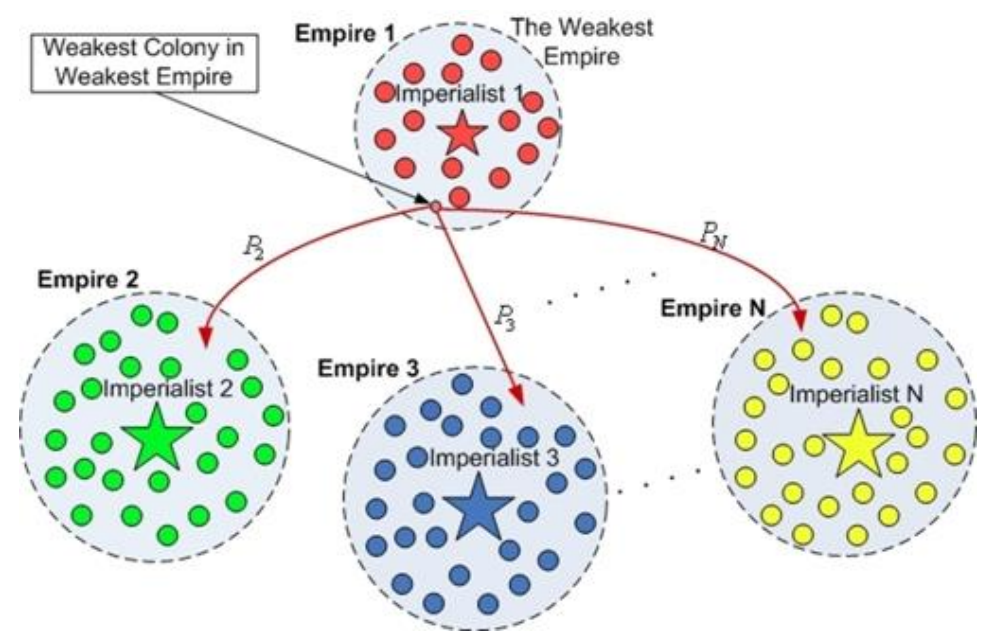

Figure 1. A Number of Random Initial Populations [16]

Then, colonies are divided among imperialist countries and enter the related Empire. Finally, according to Figure 2, colonies are assimilated to the imperialist of each Empire.

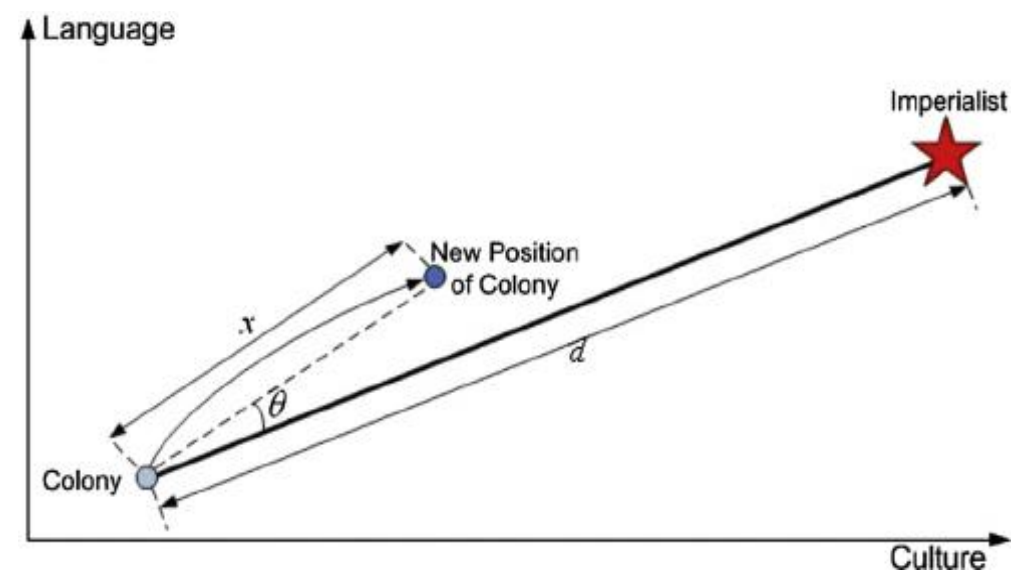

Figure 2. Assimilation Procedure [16]

In Figure 2, the distance between the imperialist and the colony has been shown with $d$, $X$ and $\theta$ are defined as random numbers with uniform distribution according to the following: 
$X \sim \mathrm{U}(0, \beta \times \mathrm{d})$

(6)

$\theta \sim \mathrm{U}(-\gamma \gamma, \gamma \gamma)$

In (6), $\beta$ is a number larger than 1 which enables the colony to approach the imperialist from different directions during its movement. According to (7), $\gamma$ is a parameter which can have an arbitrary value. If $\gamma$ is considered to be a small value, the movement of the colony toward the imperialist is a movement near the vector between the imperialist and colony, and if $\gamma$ is considered to be a large value, the colony moves toward the imperialist with a larger angle compared to the vector between the imperialist and colony. An appropriate selection for these parameters can be $\beta=2$ and $\gamma=\pi / 4$ (according to radians) [16]. During the movement of colonies toward the imperialist country, some colonies may reach to a better position (positions with less cost) than the Empire. In this case, imperialist and colony countries change their places and the algorithm continues with the imperialist country in a new position; this time, it is the new Empire country which starts to impose the assimilation policy on its colonies. The replacement of the imperialist and colony has been shown in Figure 3.

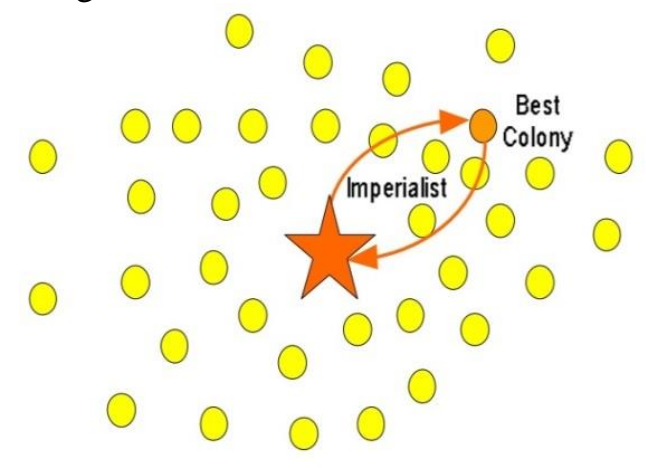

Figure 3. Replacement of the Imperialist and Colony

In Figure 3, the best colony of the Empire which has less cost than the Empire itself has been shown with a darker color. The power of each Empire is determined by the amount of power of the imperialist and its colonies. In order to model mathematical equation for the power of each Empire, it can be said that the power of each Empire is equal to the total power of the imperialist and a percentage of the total power of the colonies. By setting the formation of initial Empires, the imperialist competition begins among Empires. During this process, weak Empires (with high cost) inevitably lose their colonies and these colonies are assimilated by stronger Empires with a random probability. Finally, this process continues until weak Empires lose all of their colonies and are assimilated as a colony by the stronger Empire. Eventually, one strong Empire remains which is consisted of all colonies and the problem is converged [17].

\section{Objective Functions and Constraints}

The main aim is to introduce an optimal network configuration to reduce $\mathrm{N}_{\mathrm{sag}}$ and the mentioned reliability indices. Meanwhile, total line losses should be decreased. The objective functions are expressed as follows [18]:

$$
\begin{aligned}
& \text { Fitness }=\min (\text { Nsag }) \\
& \text { Fitness }=\min \left(\frac{\text { Nsag }}{\text { Nsag-max }}+\frac{\text { Ploss }}{\text { Ploss-max }}\right) \\
& \text { Fitness }=\min (\text { SAIFI })
\end{aligned}
$$


Fitness $=\min ($ ASIFI $)$

Fitness $=\min (\mathrm{MAIFI})$

Where, $\mathrm{N}_{\text {sag_max }}$ and $\mathrm{P}_{\text {loss_max }}$ are the maximum number of sags and maximum power loss in the system, respectively. The both are used to normalize individual objectives in the objective function. The most important constraints are the radial structure of the network, standard limits of the nominal bus voltages and acceptable limits of power loss.

\section{Simulation Results}

Reconfiguration is the act of changing default status of the tie and sectionalizing switches in the distribution network and introducing a new configuration for the network in order to satisfy objective function and constraints. In this case, each country of the imperialist competitive algorithm consists of the status of the switches. In order to avoid unfeasible solutions during optimization process, an encoding and decoding technique is suggested in [19]. So, the network always remains as a radial distribution network. Simulation is performed for a 33 bus test system in Figure 4. Table 1 contains the required information of the test distribution network.

Optimization parameters are given in Table 2. In Table 2, the necessary parameter setting for the optimization algorithm is presented. Simulation of the 33 bus test distribution system has been done in absence and presence of distributed generations. In the first mode, there are no DGs in the network and in the second mode three DGs are allocated in the bus numbers of 10,20 and 24. The rated power of the DGs is equal to $1000 \mathrm{KW}$. Table 3 determines the switches for each index. In Table 3, the tie switches before and after optimization is defined for each index separately. Figures 5 to 8 shows the voltage profile of the distribution network before and after reconfiguration for each index separately.

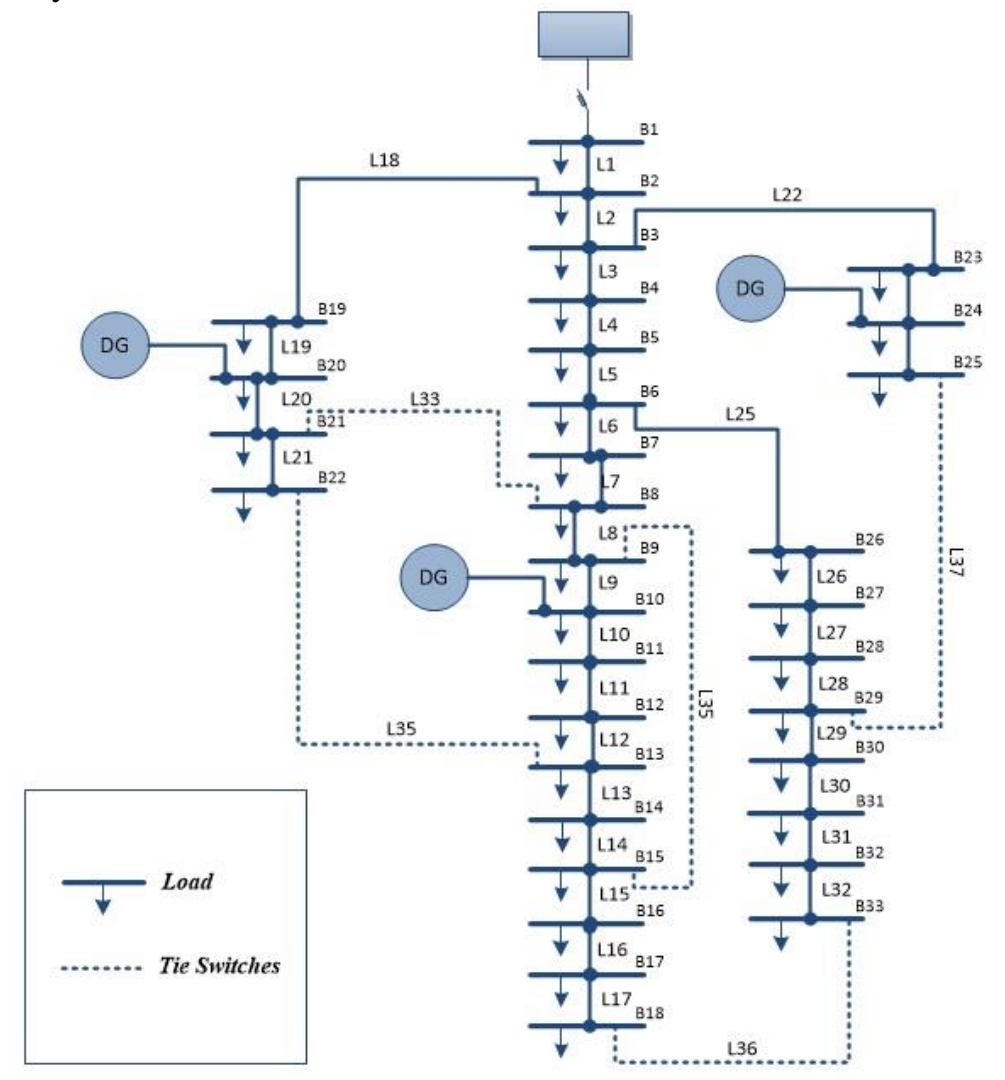

Figure 4. 33 Bus Distribution Test System 
As it can be seen in figure 5, SAIFI index is in a better condition after reconfiguration. According to Figure 6, ASIFI index has been improved on the most of the buses after reconfiguration. Figure 7 indicates improvement on MAIFI index. Also $N_{s a g}$ index has a better condition on the most of the buses according to the Figure 8. Power loss is also has been analyzed. Table 4 shows the value of power loss for optimization of each index. It's also visible that power loss has always been reduced. In this part, effect of distributed generations on the distribution network is analyzed. All of the above results are discussed again in presence of DGs with the rated power of $1000 \mathrm{KW}$ in the buses number 10, 20 and 24. Table 5 contains the selected witches for each index before and after configuration in presence of DGs. Voltage profile of the distribution network before and after reconfiguration for each index is presented in Figures 9 to 12. Presence of distributed generations can directly affect voltage profile. Figures 9 to 12 shows the voltage profile before and after reconfiguration. According to these figures, SAIFI, ASAIFI, MAIFI and $N_{s a g}$ indexes have better condition after reconfiguration even when the DGs are connected to the grid.

Table 1. Test System Data

\begin{tabular}{|c|c|c|c|c|c|c|c|c|}
\hline $\begin{array}{c}\text { Branch } \\
\text { Number }\end{array}$ & $\begin{array}{c}\text { Sending } \\
\text { Node }\end{array}$ & $\begin{array}{c}\text { Receiving } \\
\text { Node }\end{array}$ & $\mathrm{R}(\mathrm{ohm})$ & $\mathrm{X}(\mathrm{ohm})$ & $\begin{array}{c}\text { Active } \\
\text { load(kw) }\end{array}$ & $\begin{array}{c}\text { Reactive load } \\
\text { (kvar) }\end{array}$ & $\lambda$ & $\mathrm{r}$ \\
\hline 1 & 1 & 2 & 0.0922 & 0.047 & 100 & 60 & 0.8147 & 0.9229 \\
\hline 2 & 2 & 3 & 0.493 & 0.2511 & 90 & 40 & 0.9057 & 0.3499 \\
\hline 3 & 3 & 4 & 0.366 & 0.1864 & 120 & 80 & 0.1269 & 0.1965 \\
\hline 4 & 4 & 5 & 0.3811 & 0.1941 & 60 & 30 & 0.9133 & 0.2510 \\
\hline 5 & 5 & 6 & 0.819 & 0.707 & 60 & 20 & 0.6323 & 0.6160 \\
\hline 6 & 6 & 7 & 0.1872 & 0.6188 & 200 & 100 & 0.0975 & 0.4732 \\
\hline 7 & 7 & 8 & 0.7114 & 0.2351 & 200 & 100 & 0.2784 & 0.3516 \\
\hline 8 & 8 & 9 & 0.03 & 0.74 & 60 & 20 & 0.5468 & 0.8308 \\
\hline 9 & 9 & 10 & 1.044 & 0.74 & 60 & 20 & 0.9575 & 0.5852 \\
\hline 10 & 10 & 11 & 0.1966 & 0.065 & 45 & 30 & 0.9648 & 0.5497 \\
\hline 11 & 11 & 12 & 0.3744 & 0.1238 & 60 & 35 & 0.1576 & 0.9171 \\
\hline 12 & 12 & 13 & 1.648 & 1.155 & 60 & 35 & 0.9705 & 0.2858 \\
\hline 13 & 13 & 14 & 0.5416 & 0.7129 & 120 & 80 & 0.9571 & 0.7572 \\
\hline 14 & 14 & 15 & 0.591 & 0.526 & 60 & 10 & 0.4853 & 0.7531 \\
\hline 15 & 15 & 16 & 0.7463 & 0.545 & 60 & 20 & 0.8002 & 0.3804 \\
\hline 16 & 16 & 17 & 1.289 & 1.721 & 60 & 20 & 0.1418 & 0.5678 \\
\hline 17 & 17 & 18 & 0.732 & 0.574 & 90 & 40 & 0.4217 & 0.0758 \\
\hline 18 & 2 & 19 & 0.164 & 0.1565 & 90 & 40 & 0.9157 & 0.539 \\
\hline 19 & 19 & 20 & 1.5042 & 1.3554 & 90 & 40 & 0.7922 & 0.53077 \\
\hline 20 & 20 & 21 & 0.4095 & 0.4784 & 90 & 40 & 0.9594 & 0.7791 \\
\hline 21 & 21 & 22 & 0.7089 & 0.9373 & 90 & 40 & 0.6557 & 0.9340 \\
\hline 22 & 3 & 23 & 0.4512 & 0.3083 & 90 & 50 & 0.0357 & 0.1299 \\
\hline 23 & 23 & 24 & 0.898 & 0.7091 & 420 & 200 & 0.8491 & 0.5688 \\
\hline 24 & 24 & 25 & 0.896 & 0.7011 & 420 & 200 & 0.9339 & 0.4693 \\
\hline 25 & 6 & 26 & 0.203 & 0.1034 & 60 & 25 & 0.6787 & 0.0119 \\
\hline 26 & 26 & 27 & 0.2842 & 0.1447 & 60 & 25 & 0.7577 & 0.3371 \\
\hline 27 & 27 & 28 & 1.059 & 0.9337 & 60 & 20 & 0.7431 & 0.1621 \\
\hline 28 & 28 & 29 & 0.8042 & 0.7006 & 120 & 70 & 0.3922 & 0.7942 \\
\hline 29 & 29 & 30 & 0.5075 & 0.2585 & 200 & 600 & 0.6554 & 0.3112 \\
\hline 30 & 30 & 31 & 0.9744 & 0.963 & 150 & 70 & 0.1711 & 0.5258 \\
\hline 31 & 31 & 32 & 0.3105 & 0.3619 & 210 & 100 & 0.7060 & 0.1656 \\
\hline 32 & 32 & 33 & 0.341 & 0.5302 & 60 & 40 & 0.0318 & 0.6019 \\
\hline
\end{tabular}




\begin{tabular}{|c|c|c|c|c|c|c|c|c|}
\hline 32 & 8 & 21 & 2 & 2 & - & - & 0.2769 & 02669 \\
\hline 34 & 9 & 15 & 2 & 2 & - & - & 0.461 & 0.6540 \\
\hline 35 & 12 & 22 & 2 & 2 & - & - & 0.0971 & 0.6892 \\
\hline 36 & 18 & 33 & 0.5 & 0.5 & - & - & 0.8234 & 0.7481 \\
\hline 37 & 25 & 29 & 0.5 & 0.5 & - & - & 0.6948 & 0.4505 \\
\hline
\end{tabular}

Table 2. Default Value of the Parameters of the ICA

\begin{tabular}{|c|c|c|c|c|c|c|}
\hline $\begin{array}{c}\zeta \\
\text { coefficient }\end{array}$ & $\begin{array}{c}\text { Revolution } \\
\text { rate }\end{array}$ & $\begin{array}{c}\beta \\
\text { coefficient }\end{array}$ & $\begin{array}{c}\text { Number of } \\
\text { the emperor }\end{array}$ & $\begin{array}{c}\text { Population } \\
\text { size }\end{array}$ & $\begin{array}{c}\text { Number } \\
\text { of the } \\
\text { decays }\end{array}$ & $\begin{array}{c}\text { Number of } \\
\text { the variables }\end{array}$ \\
\hline 0.1 & 0.1 & 2 & 5 & 20 & 20 & 5 \\
\hline
\end{tabular}

Table 3. Tie Switches

\begin{tabular}{|c|c|c|c|c|}
\hline NR & \multicolumn{1}{|c|}{ SAIFI Index } & \multicolumn{1}{c|}{ ASIFI Index } & MAIFI Index & $\mathrm{N}_{\mathrm{sag}}$ Index \\
\hline Tie Switches before NR & $33,34,35,36,37$ & $33,34,35,36,37$ & $33,34,35,36,37$ & $33,34,35,36,37$ \\
\hline Tie Switches after NR & $7,10,14,36,37$ & $7,9,14,36,37$ & $7,11,14,36,37$ & $7,10,14,28,36$ \\
\hline
\end{tabular}

Table 4. Power Loss

\begin{tabular}{|c|c|c|c|c|}
\hline Power Loss & SAIFI Index & ASIFI Index & MAIFI Index & $\mathrm{N}_{\text {sag }}$ Index \\
\hline Before NR & 323.0322 & 323.0322 & 323.0322 & 323.0322 \\
\hline After NR & 200.6276 & 209.0657 & 202.8687 & 202.0625 \\
\hline Development percent & $37.8924 \%$ & $35.2802 \%$ & $37.1986 \%$ & $37.4482 \%$ \\
\hline
\end{tabular}

Table 5. Tie Switches in Presence of DGs

\begin{tabular}{|c|c|c|c|c|}
\hline NR & SAIFI Index & ASIFI Index & MAIFI Index & N $_{\text {sag }}$ Index \\
\hline Tie Switches before NR & $33,34,35,36,37$ & $33,34,35,36,37$ & $33,34,35,36,37$ & $33,34,35,36,37$ \\
\hline Tie Switches after NR & $7,28,32,33,34$ & $7,28,32,34,35$ & $6,11,14,28,36$ & $7,28,32,33,36$ \\
\hline
\end{tabular}

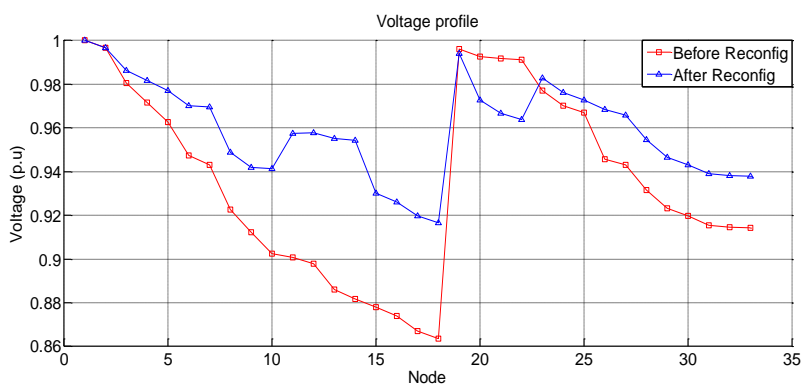

Figure 5. SAIFI Index

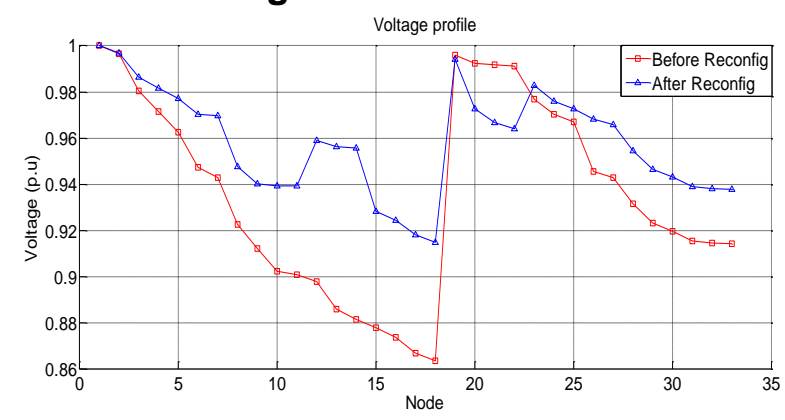

Figure 7. MAIFI Index

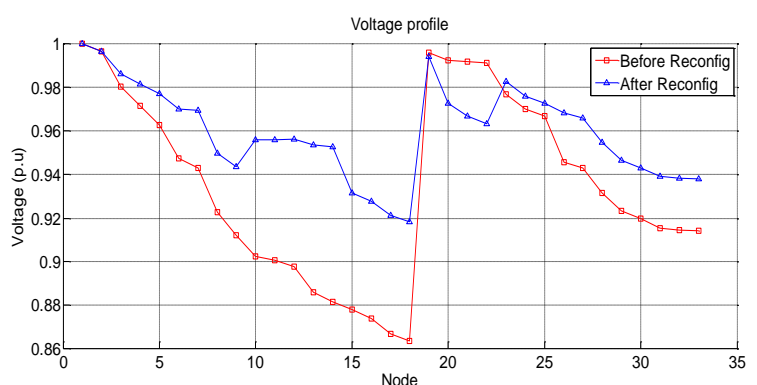

Figure 6. ASIFI Index

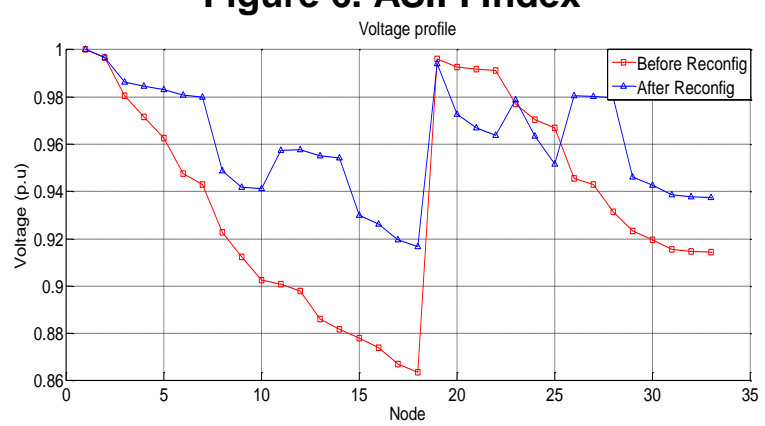

Figure 8. $\mathbf{N}_{\text {sag }}$ Index

Table 6. Power Loss in Presence of Distributed Generations 


\begin{tabular}{|c|c|c|c|c|}
\hline Power Loss & SAIFI Index & ASIFI Index & MAIFI Index & $\mathrm{N}_{\mathrm{sag}}$ Index \\
\hline Before NR & 159.9879 & 159.9879 & 159.9879 & 159.9879 \\
\hline After NR & 107.8954 & 122.3862 & 99.0349 & 107.538 \\
\hline Development percent & $32.5603 \%$ & $23.5029 \%$ & $38.0985 \%$ & $32.7837 \%$ \\
\hline
\end{tabular}

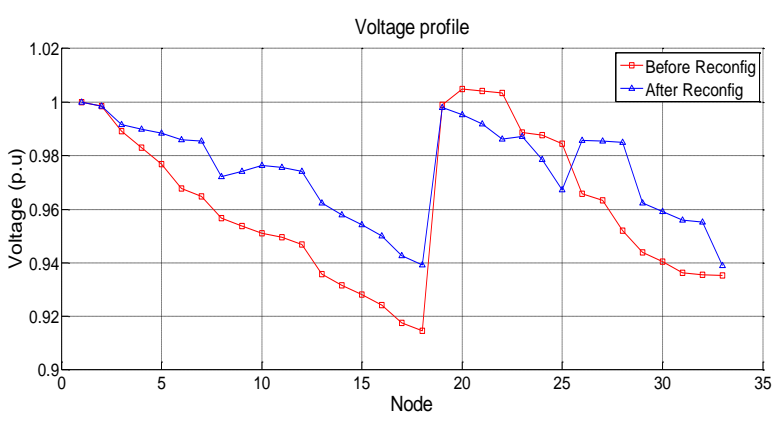

Figure 9. SAIFI Index

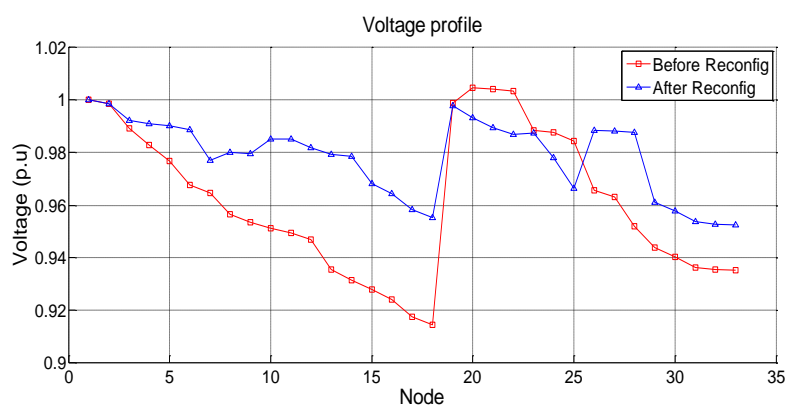

Figure 11. MAIFI Index

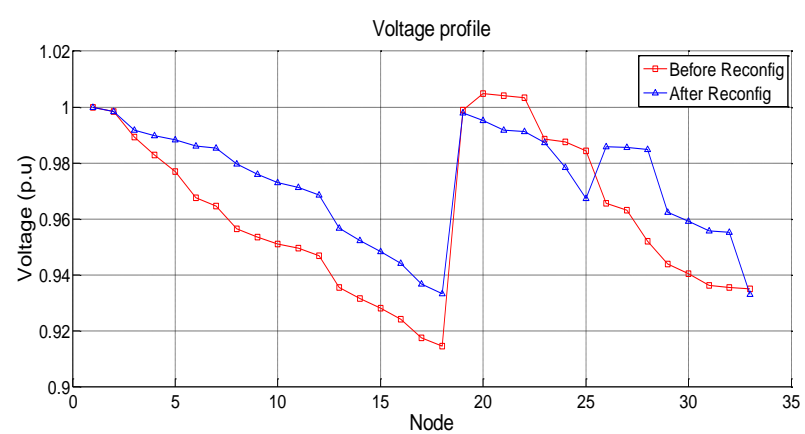

Figure 10. ASIFI Index

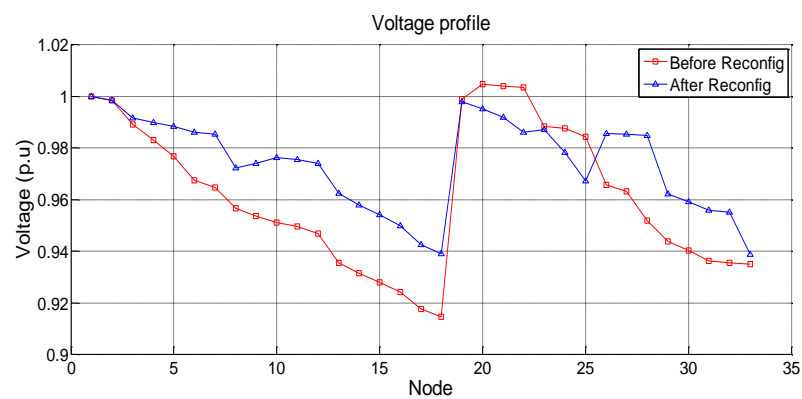

Figure 12. $\mathbf{N}_{\text {sag }}$ Index

Power loss in presence of DGs has also been developed. Table 6 shows power loss before and after optimization in distribution test system with distributed generations.

\section{Conclusions}

Network reconfiguration with different objective functions is suggested in this paper with and without distributed generations. The main goal is to enhance power quality and reliability of distribution systems. Imperialist Competitive algorithm has been hired to conduct optimization problem. Results show the effectiveness of the proposed method and all the indices are developed after reconfiguration. Tie switches and voltage profile are separately analyzed. Power loss has also been considered for each index. Simulation results in presence of distribution generation have also been analyzed and the effect of DGs as a direct power supply has been discussed in the paper. It can be concluded that Network reconfiguration can develop distribution network; but, network reconfiguration in presence of distributed generations can significantly enhance distribution system indices.

\section{References}

[1] S. Y. Yun, J. H. Oh, S. J. Rim, J. C. Kim. "Mitigation of voltage sag using feeder transfer in power distribution system." Power Engineering Society Summer Meeting, IEEE, 3 (2000), 1421-1426, 10.1109/PESS.2000.868733.

[2] J. Torres, J. L. Guardado, F. Rivas-Dávalos, S. Maximov, E. Melgoza. "A genetic algorithm based on the edge window decoder technique to optimize power distribution systems reconfiguration." International Journal of Electrical Power \& Energy Systems, 45(1) (2013): 28-34.

[3] S. Jazebi, S. H. Hosseinian, B. Vahidi. "DSTATCOM allocation in distribution networks considering 
reconfiguration using differential evolution algorithm." Energy Conversion and Management, 52.7 (2011): 2777-2783.

[4] M. Farrokhifar, S. M. Mahaei, J. Jafarzadeh, M. Gholami, "Distribution networks reconfiguration for loss minimization based on variable behavior of loads and energy cost curves", IECON, The 39th Annual Conference of the IEEE Industrial Electronics Society, Vienna, Austria, (2013).

[5] S. Nasralh, A. Mohammed, H. Shareef. "Reinforcement of power distribution network against voltage sags using graph theory." Research and Development (SCOReD), IEEE Student Conference on. (2009).

[6] C. Yao-Hsin, C. H. Chiu, Y. J. Yang. "Quantum-inspired tabu search algorithm for solving 0/1 knapsack problems." Proceedings of the 13th annual conference companion on Genetic and evolutionary computation. ACM, (2011).

[7] N. Salman, A. Mohammed, H. Shareef. "Voltage sag mitigation by combining optimal network reconfiguration and DSTATCOM placement using gravitational search algorithm." International Review of Electrical Engineering, 6(5) (2011); 2502-2512.

[8] S. Jazebi, B. Vahidi. "Reconfiguration of distribution networks to mitigate utilities power quality disturbances." Electric Power Systems Research, 91 (2012): 9-17.

[9] P. Zhang, L. Wenyuan, W. Shouxiang. "Reliability-oriented distribution network reconfiguration considering uncertainties of data by interval analysis."International Journal of Electrical Power \& Energy Systems, 34(1) (2012): 138-144.

[10] K. Sathish Kumar, T. Jayabarathi. "Power system reconfiguration and loss minimization for distribution systems using bacterial foraging optimization algorithm."International Journal of Electrical Power \& Energy Systems 36(1) (2012): 13-17.

[11] A. Kavousi-Fard, T. Niknam. "Multi-objective probabilistic distribution feeder reconfiguration considering wind power plants."International Journal of Electrical Power \& Energy Systems 55 (2014): 680-691.

[12] T. Niknam, A. Kavousi Fard, A. Baziar. "Multi-objective stochastic distribution feeder reconfiguration problem considering hydrogen and thermal energy production by fuel cell power plants."Energy, 42(1) (2012): 563-573.

[13] D. L. Brooks, R. C. Dugan, M. Waclawiak, A. Sundaram. "Indices for assessing utility distribution system RMS variation performance", IEEE Transactions Power Delivery, 13(1) (1998): 254-259.

[14] IEEE P 1159 Working Group. Recommended practice for monitoring electric power quality. Technical report, Draft 5, 1994.

[15] W. Li. Reliability assessment of electric power systems using Monte Carlo methods. Springer Science \& Business Media, 2013.

[16] E. Atashpaz-Gargari, L. Caro. "Imperialist competitive algorithm: an algorithm for optimization inspired by imperialistic competition." Evolutionary computation, CEC IEEE Congress, 2007.

[17] A Safari, A Ameli , HA Shayanfar, Nonlinear time response optimization using imperialist competitive algorithm for tuning robust power system stabilizers, IETE journal of Research, 59(5) (2013); 631-639.

[18] H. Shareef, A. A. Ibrahim, N. Salman, A. Mohamed, W. Ling Ai. "Power quality and reliability enhancement in distribution systems via optimum network reconfiguration by using quantum firefly algorithm." International Journal of Electrical Power \& Energy Systems 58 (2014): 160-169.

[19] N. Salman, A. Mohamed, H. Shareef, S. P. Ghoshal. "Optimal network reconfiguration for voltage sag mitigation in distribution systems using improved genetic algorithm" International Review of Electrical Engineering 6.3 (2011): 1356-1364

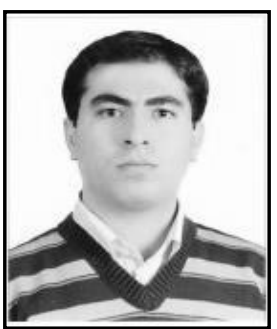

\section{Authors}

Meisam Farrokhifar. He was born in Tabriz, Iran. He received the BSc and MSc degrees from University of Tabriz in 2004 and 2007 respectively, and the PhD degree from Politecnico di Milano, Italy in 2014. Currently, he is a member of Iranian national electrotechnical committee (INEC). His fields of interest include power systems planning, energy management and electrical machines.

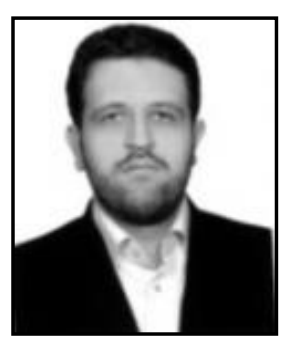

Amin Safari. He received the B.Sc. and M.Sc. degrees in Electrical Engineering in 2007 and 2009, respectively. He received his Ph.D. degree in Power Electrical Engineering, Iran University of Science and Technology, Tehran, Iran. Currently, he is an Assistant Professor in Department of Electrical Engineering, Azarbaijan Shahid Madani University, Tabriz, Iran. His areas of interest in research are 
International Journal of Grid and Distributed Computing

Vol. 9, No. 4 (2016)

Application of artificial intelligence to power system control design, FACTS device and fuzzy sets and systems. He has published more than 90 papers in international journals and conference proceedings. 